\title{
Модифицирование монтмориллонитовой глины для селективной сорбции аргона из смеси с кислородом
}

\author{
Иванова Е.Н. ${ }^{1}$, Бурмистрова Н.Н. ${ }^{1}$, Алехина М.Б. ${ }^{1}$, Дудоладов А.О. ${ }^{1}$, \\ Конькова Т.В. ${ }^{1}$, Маслова О.А. ${ }^{2}$ \\ ${ }^{I}$ Российский химико-технологический университет им. Д.И. Менделеева, Москва \\ ${ }^{2}$ Алтайский государственный университет, Барнаул
}

Поступила в редакцию 27.12.2016 г.

\begin{abstract}
Модифицированием природной монтмориллонитовой глины синтезирован адсорбент, обладающий селективностью в отношении аргона и предназначенный для удаления аргона из смеси с кислородом. Методом планирования эксперимента определены оптимальные условия получения адсорбента. Установлено, что одним из значимых факторов, влияющих на величину коэффициента разделения смеси аргон-кислород, является температура прокаливания образцов после их формования.

Ключевые слова: монтмориллонитовая глина, пилларирование, адсорбция, кислород, аргон.
\end{abstract}

\section{Modification of montmorillonite clay for the selective sorption of argon mixed with oxygen}

\author{
Ivanova E.N. ${ }^{1}$, Burmistrova N.N. ${ }^{1}$, Alekhina M.B. ${ }^{1}$, Dudoladov A.O. ${ }^{1}$, \\ Kon'kova T.V. ${ }^{1}$, Maslova O.A. ${ }^{2}$ \\ ${ }^{I}$ D.I. Mendeleyev University of Chemical Technology of Russia, Moscow \\ ${ }^{2}$ Altai State University, Barnaul
}

The purpose of this study was to determine optimal conditions for the synthesis of adsorbent based on montmorillonite clays for the selective adsorption of argon from its mixture with oxygen. To determine the conditions for modification of the samples was used the method of experiment planning. The independent factors were chosen: the ratio $\mathrm{Al}^{3+} / \mathrm{OH}^{-}$; the temperature of ion exchange; the drying temperature; the calcinations temperature; the ratio $\mathrm{Al}^{3+} / \mathrm{Cr}^{3+}$. The area values were as follows: the ratio $\mathrm{Al}^{3+} / \mathrm{OH}^{-}$1:2.0-1:2.4; the temperature of ion exchange $25-75^{\circ} \mathrm{C}$; ; the drying temperature $25-$ $85^{\circ} \mathrm{C}$; the calcinations temperature $400-550^{\circ} \mathrm{C}$; the ratio $\mathrm{Al}^{3+} / \mathrm{Cr}^{3} 0-1$. Parameter optimization was the separation factor a gas mixture of argon-oxygen, which is calculated as the ratio of the equilibrium adsorption capacity of argon and oxygen. The paper presents the elemental composition, structural and energy characteristics and data on the adsorption of argon and oxygen on prepared samples. The optimal parameters of medication clays: the ratio $\mathrm{Al}^{3+} / \mathrm{OH}^{-}$1:2.0-1:2.0; the temperature of ion exchange $75^{\circ} \mathrm{C}$; ; the drying temperature $25^{\circ} \mathrm{C}$; the calcinations temperature $550^{\circ} \mathrm{C}$; the ratio $\mathrm{Al}^{3+} / \mathrm{Cr}^{3} 0$. The result of pillaring in optimum conditions was obtained the Al-PILC sample with equilibrium adsorption of oxygen and argon 4.50 and $6.70 \mathrm{~cm}^{3} / \mathrm{g}$, respectively; the separation factor was 1.5 .

Keywords: montmorillonite clay, pillaring, adsorption, oxygen, argon.

\section{Введение}

Необходимость в автономном обеспечении производств кислородом способствует развитию адсорбционного метода разделения воздуха. Максимально возмож- 
ная чистота кислорода, получаемого в адсорбционных установках, составляет 95.7 об. \% (4.3 об. \% приходится на аргон) [1]. Однако вследствие близости адсорбционных свойств аргона и кислорода чрезвычайно сложно разделить их смесь на существующих промышленных адсорбентах. Увеличение чистоты кислорода способствовало бы расширению области применения кислородных адсорбционных установок [24]. Кислород высокой чистоты требуется для решения большого количества различных задач в металлообработке, медицине, фармацевтической промышленности, горнодобывающей промышленности и других отраслях.

По классификации молекул по их способности к различным видам взаимодействия А.В. Киселева [5] аргон относится к группе А. Аргон - молекула со сферически симметричной электронной оболочкой, взаимодействует с поверхностью адсорбентов только за счет неспецифических сил, в основном дисперсионного притяжения. Кислород, в свою очередь, относится к группе В, благодаря тому, что он обладает слабым квадрупольным моментом. Молекула кислорода взаимодействует с поверхностью адсорбентов за счет неспецифических сил и специфических сил (ориентация диполей и квадруполей, донорно-акцепторные связи).

Поскольку аргона в кислородообогащенном потоке всего 5 об. \%, то для удаления этой примеси актуальным остается поиск высокоактивных в отношении аргона типов адсорбентов. В работах [6-7] приведен обзор литературы по этой теме и результаты наших исследований по разработке адсорбентов, селективных по отношению к аргону. Одним из перспективных материалов, проявивших селективность к аргону, оказалась столбчатая (пиллар-) глина на основе монтмориллонита [7]. Схема кристаллической структуры монтмориллонита приведена на рис. 1.

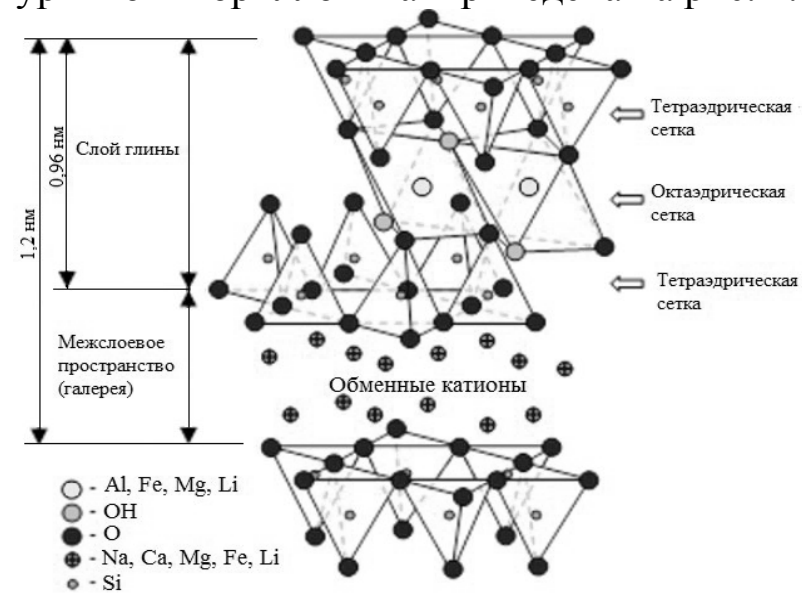

Рис. 1. Схема кристаллической структуры монтмориллонита

Синтез пиллар-глин или PILC-сорбентов (pillared interlayer clay-сорбентов) на основе слоистых силикатов и основных солей алюминия, титана, хрома и др. был осуществлен в 70-е годы прошлого века [8]. Наибольшее распространение получили микропористые сорбенты на основе монтмориллонита и основных солей алюминия. В основе их получения лежит реакция замещения межслоевых катионов $\mathrm{Na}^{+}$или $\mathrm{Ca}^{2+}$ исходного минерала на олигомерные катионы составов от $\left[\mathrm{Al}_{13} \mathrm{O}_{4}(\mathrm{OH})_{24}\left(\mathrm{H}_{2} \mathrm{O}\right)_{12}\right]^{7+}$ до $\left[\mathrm{Al}_{13} \mathrm{O}_{4}(\mathrm{OH})_{30}\left(\mathrm{H}_{2} \mathrm{O}\right)_{6}\right]^{+}$[9]. Среди этих катионов наиболее устойчивым в водном растворе в интервале $\mathrm{pH} 3.7-4.3$ и мольном отношении $\mathrm{OH}^{-} / \mathrm{Al}^{3+} n=1.2-2.3$ считается катион $\left[\mathrm{Al}_{13} \mathrm{O}_{4}(\mathrm{OH})_{28}\left(\mathrm{H}_{2} \mathrm{O}\right)_{8}\right]^{3+}[10]$.

Суть метода пилларирования (частный случай интеркалирования) заключается в обмене межслоевых катионов глины на полигидроксокатионы различной природы $\left(\mathrm{Al}^{3+}, \mathrm{Fe}^{3+}, \mathrm{Ti}^{4+}, \mathrm{Zr}^{4+}\right.$ и др). При последующей термообработке, комплексные катионы переходят в соответствующие оксиды металлов, которые, действуя как опо- 
ры, фиксируют на определённом расстоянии силикатные слои, создавая тем самым регулярные пористые структуры. Во время прокаливания при повышенных температурах полигидроксокатионы преобразуются в твердые оксидные столбцы, при этом высвобождаются протоны, которые мигрируют в силикатных слоях, становясь недоступными для ионного обмена. Это приводит к снижению ионообменной емкости пилларированных глин по сравнению с исходными [11].

В настоящее время разработке методов получения, изучению свойств и вопросам практического применения PILC-сорбентов посвящены многие десятки статей и патентов [12]. Однако статей, посвященных адсорбции газов на пилларированных глинах сравнительно немного, например, [11,13-15].

В работе [16] методом пилларирования синтезированы материалы с микропористой структурой из природной монтмориллонитовой глины Таганского месторождения (Восточный Казахстан). С помощью метода планирования эксперимента проведена оптимизация условий пилларирования для получения катализаторов и адсорбентов с максимальным значением объема микропор.

В настоящей работе приведены результаты модифицирования монтмориллонитовой глины для получения адсорбента, обладающего селективностью в отношении аргона и предназначенного для удаления аргона из смеси с кислородом. Целью исследования было выделение значимых факторов, влияющих на коэффициент разделения аргон-кислород и определение оптимальных условий модифицирования глины в диапазоне исследования.

\section{Эксперимент}

В качестве исходного материала использовалась глина Таганского месторождения (Республика Казахстан) с содержанием монтмориллонита 90-98\%, предоставленная ООО «Алтайская сырьевая компания». Исходная глина - образец горизонта № 3 месторождения Таганское, из которого была отсеяна фракция частиц 0.25$0.5 \mathrm{MM}$.

Для определения условий модифицирования образцов монтмориллонитовой глины с целью получить материал, обладающий селективностью к аргону, применили план Плакетта - Бермана. План позволяет получать раздельные оценки линейных ортогональных эффектов всех факторов с максимально возможной при данном числе опытов точностью, одинаковой для всех эффектов [17]. Была построена матрица планирования размером $12 \times 6$. В качестве независимых факторов были выбраны: $x_{1}-$ соотношение $\mathrm{Al}^{3+} / \mathrm{OH}^{-} ; x_{2}$ - температура ионного обмена, ${ }^{o} C ; x_{3}$ - температура сушки, ${ }^{\circ} \mathrm{C} ; x_{4}$ - температура прокаливания, ${ }^{\circ} \mathrm{C} ; x_{5}$ - соотношение $\mathrm{Al}^{3+} / \mathrm{Cr}^{3+}$ (табл. 1 ).

Таблица 1. Матрица планирования

\begin{tabular}{|c|c|c|c|c|c|}
\hline № & $x_{1}$ & $x_{2},{ }^{\circ} \mathrm{C}$ & $x_{3},{ }^{\circ} \mathrm{C}$ & $x_{4},{ }^{\circ} \mathrm{C}$ & $x_{5}$ \\
\hline 1 & $1: 2.4$ & 25 & 85 & 400 & 0 \\
\hline 2 & $1: 2.4$ & 75 & 25 & 550 & 0 \\
\hline 3 & $1: 2.0$ & 75 & 85 & 400 & 1 \\
\hline 4 & $1: 2.4$ & 25 & 85 & 550 & 0 \\
\hline 5 & $1: 2.4$ & 75 & 25 & 550 & 1 \\
\hline 6 & $1: 2.4$ & 75 & 85 & 400 & 1 \\
\hline 7 & $1: 2.0$ & 75 & 85 & 550 & 0 \\
\hline 8 & $1: 2.0$ & 25 & 85 & 550 & 1 \\
\hline 9 & $1: 2.0$ & 25 & 25 & 550 & 1 \\
\hline 10 & $1: 2.4$ & 25 & 25 & 400 & 1 \\
\hline 11 & $1: 2.0$ & 75 & 25 & 400 & 0 \\
\hline 12 & $1: 2.0$ & 25 & 25 & 400 & 0 \\
\hline
\end{tabular}

Иванова и др. / Сорбционные и хроматографические процессы. 2017. Т. 17. № 4 
Области исследования параметров процесса (соотношения реагентов, температуры) были выбраны на основании литературных данных и предварительных экспериментальных исследований [18-19]. Соотношение $\mathrm{Al}^{3+} / \mathrm{Cr}^{3+}$ было введено в план, чтобы расширить диапазон модифицирующих элементов путем введения в межслоевое пространство монтмориллонита кластеров оксидов переходных металлов и исследовать влияние переходного металла в структуре Cr/Al-PILC на селективность к аргону. Области значений составили: соотношения $\mathrm{Al}^{3+} / \mathrm{OH}^{-} 1: 2.0-1: 2.4$, температуры ионного обмена $25-75^{\circ} \mathrm{C}$, температуры сушки $25-85^{\circ} \mathrm{C}$, температуры прокаливания $400-550^{\circ} \mathrm{C}$, соотношения $\mathrm{Al}^{3+} / \mathrm{Cr}^{3+} 0-1$. Оба уровня варьирования (верхний и нижний) для каждого фактора взяты в соответствии с литературными данными и ранее проведенными экспериментами.

В качестве параметра оптимизации (y) рассматривался коэффициент разделения газовой смеси аргон-кислород, который рассчитывали, как соотношение равновесных емкостей аргона и кислорода.

Подробно, использованная нами методика пилларирования глин, описана в [20]. В процессе приготовления модифицирующего раствора исходный водный раствор 0.2M $\mathrm{AlCl}_{3}$ подвергался гидролизу путём капельного введения $\mathrm{NaOH}$ до соотношений, согласно плану. Для образцов глины, содержащих хром, раствор был приготовлен путем смешения $0.2 \mathrm{M}$ растворов $\mathrm{AlCl}_{3}$ и $\mathrm{Cr}\left(\mathrm{NO}_{3}\right)_{3}$ в соотношении 1:1. Гидролиз проводили при $60^{\circ} \mathrm{C}$. В процессе прибавления щёлочи раствор интенсивно перемешивали для предотвращения локальных пересыщений. Среднее время гидролиза составило 2-2.5 ч. Полученный раствор подвергали старению в течение 7 сут.

Для ионного обмена исследуемую глину смешивали с модифицирующим раствором и интенсивно перемешивали в течение 4 ч при температурах, согласно плану. В дальнейшем образцы оставляли под слоем модифицирующего раствора на 2 ч, после чего промывали дистиллированной водой и подвергали сушке. Сушку образцов осуществляли на открытом воздухе при комнатной температуре, либо в сушильном шкафу при $85^{\circ} \mathrm{C}$ до полного испарения влаги. Таблетирование образцов осуществляли без связующего методом сухого формования. Таблетки глины были получены с помощью гидравлического пресса Crush IR производства фирмы PTKE Technologies при давлении 300 кг и 780 кг. Полученные в процессе формования таблетки дробили на частицы, отбирали фракцию 1.0-2.0 мм. Прокаливание проводили в атмосфере воздуха при температурах, согласно плану. Нагревание осуществляли со скоростью 5 град/мин, время выдержки - 2 ч.

Для определения структурно-энергетических характеристик образцов пилларированной глины снимали изотермы адсорбции азота при 77 К на объемной установке Nova 1200e (Quantachrome, CША). Перед измерением изотерм проводили дегазацию образцов при $300^{\circ} \mathrm{C}$ и остаточном давлении $10^{-3}$ мм рт. ст. в течение 4 ч. Удельную поверхность $\left(S_{\text {уд }}\right)$ образцов рассчитывали по уравнению БЭТ, объем адсорбционного пространства микропор и характеристическую энергию адсорбции $\left(W_{0}, E_{0}\right)$ рассчитывали по уравнению Дубинина-Радушкевича. Суммарный сорбционный объем мезо- и микропор $\left(V_{\mathrm{s}}\right)$ определяли по изотерме адсорбции азота при значении относительного давления, равном 0.995 .

В статье [16] приведены изотермы адсорбции азота при 77 К на природных и модифицированных образцах монтмориллонитовой глины Таганского месторождения в линейных координатах уравнения Дубинина-Радушкевича. Показано, что данное уравнение во всем диапазоне значений относительного давления описывает экспериментальные данные по адсорбции азота на пилларированных образцах глин. 
Элементный состав образцов определяли рентгенофлуоресцентным методом с помощью приставки X-MAX INCA ENERGY (Oxford Instruments, Великобритания) к электронному микроскопу JEOL JSM-6510 LV (JEOL, Япония) в Центре коллективного пользования имени Д.И. Менделеева.

Равновесные емкости по кислороду и аргону были определены на основании кинетических кривых адсорбции этих газов при $25^{\circ} \mathrm{C}$ и атмосферном давлении, снятых на волюмометрической установке.

\section{Обсуждение результатов}

Результаты элементного анализа исходной глины и модифицированных образцов приведены в табл. 2.

Таблица 2. Результаты элементного анализа образцов исходного и модифицированного монтмориллонита

\begin{tabular}{|c|c|c|c|c|c|c|c|c|c|c|c|}
\hline $\begin{array}{c}\text { Элемент/ } \\
\text { Образец }\end{array}$ & $\mathrm{O}$ & $\mathrm{Mg}$ & $\mathrm{Al}$ & $\mathrm{Si}$ & $\mathrm{Ti}$ & $\mathrm{Cr}$ & $\mathrm{Fe}$ & $\mathrm{Na}$ & $\mathrm{S}$ & $\mathrm{Cl}$ & $\mathrm{Ca}$ \\
\hline $\begin{array}{c}\text { Глина } \\
\text { Исходная }\end{array}$ & \multicolumn{10}{|c|}{ Содержание элемента, мас. \% } \\
\cline { 2 - 16 } & 59.24 & 1.60 & 9.96 & 23.98 & 0.36 & - & 3.80 & 0.52 & 0.03 & 0.14 & 0.36 \\
\hline \multicolumn{10}{|c|}{ Модифицированные образцы } \\
\hline №1 & 59.69 & 1.71 & 14.06 & 22.41 & 0.23 & - & 1.89 & - & - & - & - \\
\hline №2 & 60.46 & 1.61 & 13.75 & 20.99 & 0.19 & - & 2.95 & 0.07 & - & - & - \\
\hline №3 & 55.35 & 1.73 & 9.61 & 23.67 & 0.12 & 6.95 & 2.57 & - & - & - & - \\
\hline №4 & 59.72 & 1.58 & 13.71 & 21.83 & 0.23 & - & 2.91 & 0.06 & - & - & - \\
\hline №5 & 57.38 & 1.66 & 13.30 & 24.30 & 0.33 & 0.20 & 2.84 & - & - & - & - \\
\hline №6 & 56.28 & 1.56 & 9.94 & 21.24 & 0.18 & 8.62 & 2.18 & - & - & - & - \\
\hline №7 & 57.51 & 1.61 & 12.47 & 25.22 & 0.24 & - & 2.95 & - & - & - & - \\
\hline №8 & 54.58 & 1.66 & 9.16 & 24.80 & 0.41 & 6.09 & 3.28 & - & - & - & - \\
\hline №9 & 58.24 & 1.49 & 10.45 & 23.17 & 0.21 & 4.29 & 2.15 & - & - & - & - \\
\hline №10 & 56.12 & 1.49 & 9.65 & 22.66 & - & 7.33 & 2.75 & - & - & - & - \\
\hline №11 & 58.33 & 1.57 & 12.14 & 24.77 & 0.11 & - & 3.08 & - & - & - & - \\
\hline №12 & 58.54 & 1.58 & 11.91 & 24.28 & 0.32 & - & 3.37 & - & - & - & - \\
\hline
\end{tabular}

Как видно из табл. 2, модифицирование монтмориллонита привело к удалению из материала катионов $\mathrm{Ca}^{2+}$ и $\mathrm{Na}^{+}$, которые являются активными центрами сорбции кислорода. Это должно способствовать повышению селективности адсорбентов Al-PILC и Cr/Al-PILC к аргону. В результате модифицирования увеличилось содержание алюминия в образцах Al-PILC в 1,5 раза, в образцах же Cr/Al-PILC оно практически не изменилось относительно исходного, за исключением образца № 5, где оно существенно возросло. Содержание таких элементов, как Fe и Ti снизилось немного, ввиду их изоморфного замещения алюминием в кристаллической структуре монтмориллонита.

Изотермы адсорбции азота при 77 К на образцах модифицированной глины приведены на рис. 2.

Пример кинетических кривых адсорбции аргона и кислорода для образца № 4 Al-PILC, полученных на волюмометрической установке при $25^{\circ} \mathrm{C}$ и $0.1 \mathrm{MПа,} \mathrm{приве-}$ ден на рис. 3. Для этого образца характерны более высокая скорость адсорбции аргона и существенно более высокое значение равновесной емкости аргона по сравнению с кислородом.

Структурно-энергетические характеристики образцов глин и средние значения величин адсорбции газов и коэффициента разделения $\left(K_{\mathrm{p}}\right)$ по результатам двух измерений приведены в табл. 3. 

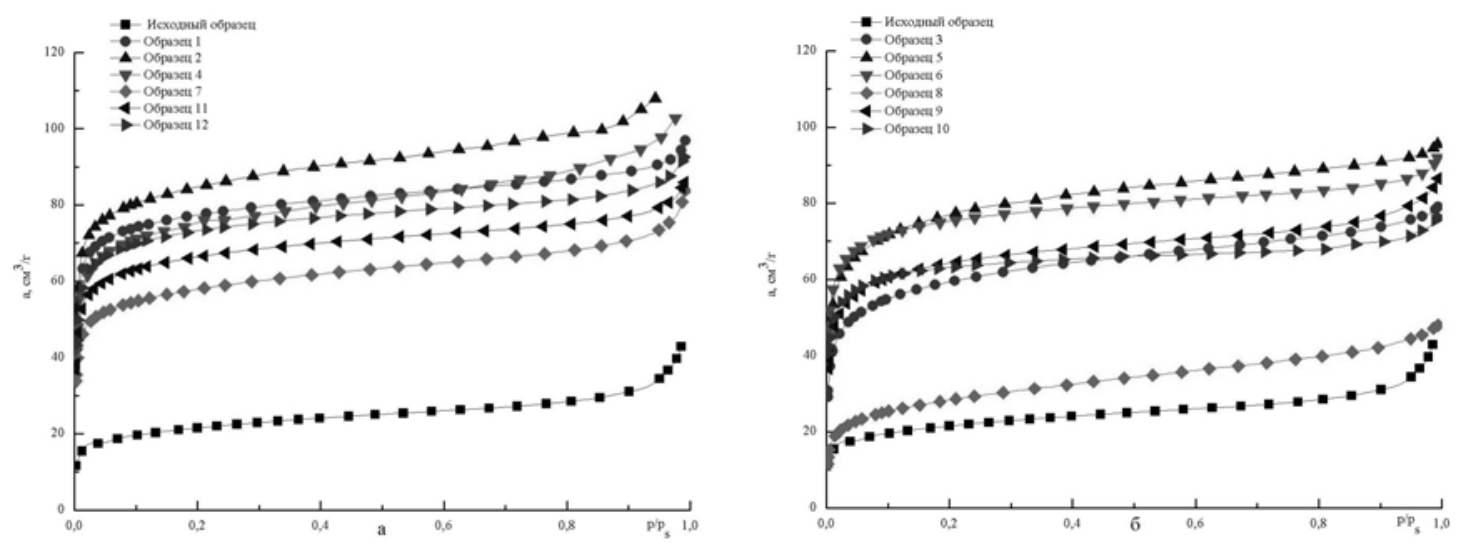

Рис. 2. Изотермы адсорбции азота при 77 К на образцах модифицированной глины: a - Al-PILC, б - Cr/Al-PILC.

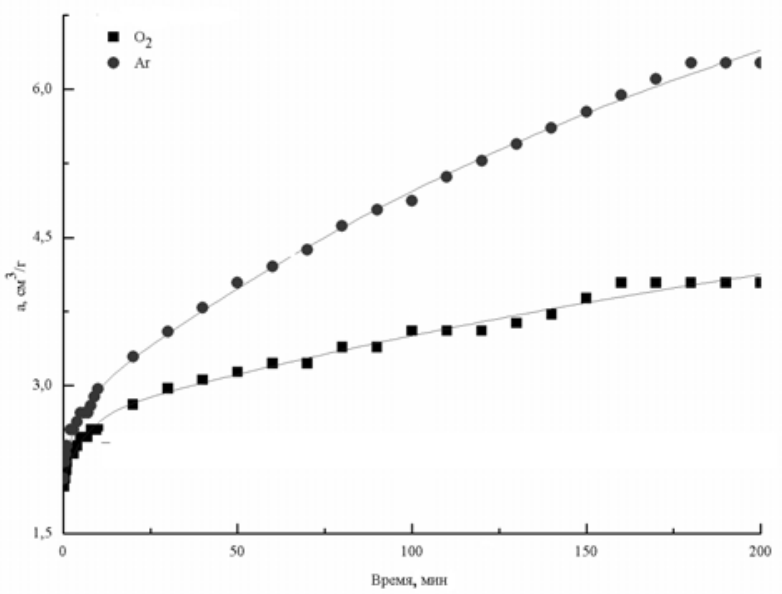

Рис. 3. Кинетические кривые адсорбции кислорода и аргона на образце № 4 Al-PILC

Таблица 3. Структурно-энергетические характеристики, равновесные величины адсорбции и коэффициенты разделения смеси аргон-кислород образцов исходной и модифицированной глины

\begin{tabular}{|c|c|c|c|c|c|c|c|c|}
\hline № & Образец & $\begin{array}{c}\mathrm{S}_{\text {уд, }} \\
\mathrm{м}^{2} / \Gamma\end{array}$ & $\begin{array}{c}\mathrm{E}_{0}, \\
\text { кДж/моль }\end{array}$ & $\begin{array}{c}\mathrm{W}_{0}, \\
\mathrm{~cm}^{3} / \Gamma\end{array}$ & $\begin{array}{c}\mathrm{V}_{\mathrm{s}}-\mathrm{W}_{0}, \\
\mathrm{~cm}^{3} / \Gamma\end{array}$ & \multicolumn{2}{|c|}{$\begin{array}{c}\text { Равновесная ад- } \\
\text { сорбция }\left(25{ }^{\circ} \mathrm{C} \text { и }\right. \\
0.1 \mathrm{MПа}), \mathrm{cm}^{3} / \Gamma\end{array}$} & $\begin{array}{c}\mathrm{Kр} \\
\mathrm{Ar} / \mathrm{O}_{2}\end{array}$ \\
\hline- & $\begin{array}{c}\text { Исходная } \\
\text { глина }\end{array}$ & 78 & 12.4 & 0.04 & - & $\mathrm{O}_{2}$ & $\mathrm{Ar}$ & - \\
\hline 1 & Al-PILC & 243 & 15.1 & 0.12 & 0.03 & 4.99 & 3.72 & 0.7 \\
\hline 2 & Al-PILC & 268 & 14.5 & 0.13 & 0.04 & 5.09 & 5.91 & 1.2 \\
\hline 3 & Cr/Al-PILC & 192 & 12.0 & 0.09 & 0.03 & 2.85 & 3.58 & 1.3 \\
\hline 4 & Al-PILC & 236 & 13.0 & 0.12 & 0.03 & 4.04 & 6.27 & 1.5 \\
\hline 5 & Cr/Al-PILC & 247 & 11.9 & 0.12 & 0.03 & 5.44 & 5.62 & 1.0 \\
\hline 6 & Cr/Al-PILC & 237 & 13.5 & 0.12 & 0.02 & 5.62 & 5.25 & 0.9 \\
\hline 7 & Al-PILC & 184 & 14.5 & 0.09 & 0.04 & 5.20 & 6.44 & 1.2 \\
\hline 8 & Cr/Al-PILC & 95 & 11.0 & 0.04 & 0.03 & 5.60 & 3.70 & 0.7 \\
\hline 9 & Cr/Al-PILC & 204 & 12.2 & 0.10 & 0.03 & 3.27 & 4.16 & 1.3 \\
\hline 10 & Cr/Al-PILC & 196 & 13.8 & 0.10 & 0.02 & 3.91 & 3.88 & 1.0 \\
\hline 11 & Al-PILC & 209 & 14.6 & 0.10 & 0.03 & 5.83 & 6.85 & 1.2 \\
\hline 12 & Al-PILC & 231 & 14.4 & 0.12 & 0.02 & 6.06 & 7.36 & 1.2 \\
\hline
\end{tabular}


Как следует из представленных результатов, после модифицирования образцы глины обладали микропористой структурой. У всех модифицированных образцов произошло существенное изменение их пористой структуры по сравнению с исходной глиной: увеличение значений удельной поверхности и объема микропор (в 2-3 раза), за исключением образца № 8 (Cr/Al-PILC). Объем мезопор, рассчитанный как разность $V_{\mathrm{s}}$ и $W_{0}$, для всех образцов был практически одинаковым. Наименьшими значениями характеристической энергии обладали образцы № 5 и № 8 с содержанием хрома 0.2 и 6.1 мас. \%, соответственно. Эти образцы существенно (в 2.5 раза) отличались по значениям $S_{\text {уд }}$, и обладали близкими значениями $E_{\text {о }}(11.9$ и 11.0 кДж/моль для образцов № 5 и № 8, соответственно), но при этом адсорбция кислорода на образце № 5 была такой же, как и аргона, а на образце № 8 - лучше, чем аргона. На основании этих результатов мы сделали вывод, что введение второго металла (хрома), помимо алюминия, при пилларировании глины, привело к созданию новых центров адсорбции кислорода и способствовало увеличению его адсорбции по сравнению с аргоном.

По экспериментальным результатам, как следует из табл. 3, наибольшее значение коэффициента разделения смеси аргон-кислород было получено на образце модифицированного монтмориллонита Al-PILC под № 4, равное 1.5. Сопоставляя данные табл. 2 и 3, мы не установили каких-либо четких корреляций значений коэффициента разделения смеси аргон-кислород (y) со структурно-энергетическими характеристиками и элементным составом полученных образцов адсорбентов.

Для определения оптимальных условий модифицирования и интенсивности влияния выбранных факторов далее был проведен регрессионный анализ результатов эксперимента.

В центре плана предварительно определили дисперсию воспроизводимости значений $y$ по трем параллельным опытам. Дисперсия воспроизводимости с числом степеней свободы $f=2$ была равна 0,0177 .

Полученное линейное уравнение регрессии, без исключения незначимых коэффициентов:

$$
\hat{y}=1.103-0.0306 x_{1}+0.0271 x_{2}-0.0374 x_{3}+0.0514 x_{4}-0.07575 x_{5}
$$

Оптимальные условия: $-1\left(\mathrm{Al}^{3+} / \mathrm{OH}^{-}=1: 2.0\right)+1\left(75^{\circ} \mathrm{C}\right)-1\left(25^{\circ} \mathrm{C}\right)+1\left(550{ }^{\circ} \mathrm{C}\right)-1$ $\left(\mathrm{Al}^{3+} / \mathrm{Cr}^{3+}=0\right)$. Лучший опыт в эксперименте № 4: $+1\left(\mathrm{Al}^{3+} / \mathrm{OH}^{-}=1: 2.4\right)-1\left(25^{\circ} \mathrm{C}\right)$ $+1\left(85^{\circ} \mathrm{C}\right)+1\left(550^{\circ} \mathrm{C}\right)-1\left(\mathrm{Al}^{3+} / \mathrm{Cr}^{3+}=0\right)$, для него не совпадают $1,2,3$ факторы, совпадают 4 и 5 факторы.

Значимость коэффициентов оценивали по критерию Стьюдента. Табличное значение критерия Стьюдента $t_{0,05}(11)=2.2$ с числом степеней свободы $f=11$.

После исключения незначимых коэффициентов уравнение регрессии приняло вид:

$$
\hat{y}=1.103+0.0514 x_{4}-0.07575 x_{5}
$$

Из линейного уравнения регрессии видно, что оптимальным условиям соответствует не только образец № 4, но и образцы № 2 и № 7. Таким образом, образец № 4, который был лучшим в эксперименте, является таковым по уравнению (2).

Адекватность уравнения (2) эксперименту проверили по критерию Фишера. Дисперсия адекватности, $S_{\text {ад }}^{2}$ с числом степеней свободы $f=9$ равна 0,062 . Fотношение равно: $\mathrm{F}=\mathrm{S}_{\text {ад }}^{2} / \mathrm{S}_{\text {воспр }}^{2} \mathrm{~F}=3.52$. Табличное значение критерия Фишера для $p=0,05, f_{1}=9$ (12 опытов -3 значимых коэффициента) и $f_{2}=2$ (3 параллельных опыта $1), F_{0.95}(9.2)=19.3 . F<\mathrm{F}_{0.95}(9.2)$. Таким образом, линейное уравнение регрессии адекватно эксперименту.

Итак, на выходную величину (коэффициент разделения смеси $\mathrm{Ar}-\mathrm{O}_{2}$ ) не влияют соотношение $\mathrm{Al}^{3+} / \mathrm{OH}^{-}$, температура ионного обмена и температура сушки в 
области исследования. В качестве значимых коэффициентов были выделены следующие факторы: температура прокаливания и соотношение $\mathrm{Al}^{3+} / \mathrm{Cr}^{3+}$. Характер влияния факторов разный, однако интенсивность их влияния на коэффициент разделения примерно одинакова. Увеличение температуры прокаливания в выбранном диапазоне приводит к увеличению выходной величины, увеличение же соотношения $\mathrm{Al}^{3+} / \mathrm{Cr}^{3+}$, напротив, вызывает снижение значений выходной величины. Такой результат говорит о том, что в области исследования процесс устойчив к колебаниям параметров.

Из проведенного исследования вытекает, что температура прокаливания является важным фактором модифицирования глины, влияющим на формирование ее микропористой структуры и адсорбционные свойства по кислороду и аргону.

Отрицательное влияние увеличения соотношения $\mathrm{Al}^{3+} / \mathrm{Cr}^{3+}$ на коэффициент разделения объясняется тем, что введение хрома в пиллары приводит к образованию специфических мест адсорбции кислорода в порах адсорбента.

В полученных оптимальных условиях был проведен дополнительный эксперимент. В результате пилларирования в оптимальных условиях был получен образец Al-PILC со значениями равновесной адсорбции по кислороду и аргону 4.50 и 6.70 $\mathrm{cm}^{3} / \Gamma$, соответственно; и коэффициентом разделения 1.5 .

\section{Заключение}

Методом пилларирования из природной монтмориллонитовой глины синтезирован адсорбент Al-PILC, обладающий селективностью в отношении аргона и предназначенный для удаления аргона из смеси с кислородом. Показано, что удаление катионов кальция и натрия из межпакетного пространства монтмориллонита при его модифицировании приводит к возрастанию адсорбции аргона по сравнению с кислородом. С помощью метода планирования эксперимента определены оптимальные условия получения адсорбента: соотношение $\mathrm{Al}^{3+} / \mathrm{OH}^{--}=1: 2.0$; температура ионного обмена $75{ }^{\circ} \mathrm{C}$; температура сушки $25^{\circ} \mathrm{C}$; температура прокаливания $550^{\circ} \mathrm{C}$; соотношение $\mathrm{Al}^{3+} / \mathrm{Cr}^{3+}=0$.

Авторы благодарят к.х.н. А.Н. Морозова (РХТУ им. Д.И. Менделеева) за выполненные им анализы образцов.

\section{Список литературы}

1. Шумяцкий Ю.И. Промышленные адсорбционные процессы. М. КолосС. 2009.184 c.

2. Степанова М.А. // Специализированный журнал «РИТМ». 2012. Т. 72. № 4. С. 102104.

3. Акулов А.К. // Сфера. Нефть и газ. 2014. T. 42. № 4. С. 38-42.

4. Васильев А.А. // Индустрия. 2010. Т. 98. № 4. C. 44-45.

5. Киселев А.В. Межмолекулярные взаимодействия в адсорбции и хроматографии. М. Высшая школа. 1986. 360 с.

6. Алехина М.Б., Конькова Т.В. // Вестник ВГУ, серия: химия, биология, фармачия. 2011. № 2. C. 67-74.

7. Вахрушева Е.М., Иванова Е.Н., Алехина М.Б., Конькова Т.В.и др. // Успехи в химии и химической технологии. 2013. Т. 27. № 7 (147). C. 80-84.

8. Brindley G.W., Sempels R.E. // Clays and Clay Minerals. 1977. Vol. 12. No. 3. pp. 229237.

9. Scnoonheydt R.A., van den Eynde G., Tubbax H. et al. // Clays and Clay Minerals. 1993. Vol. 41. No 5. pp. 598-607.

10. Bottero J.Y., Cases J.M., Flessinger F., Polrler J.E. // J. Phys.Chem. 1980. Vol. 84. No. 22. pp. 2933-2939.

11. Zhu H., Lu G. // Journal of Porous Materials. 1998. Vol. 5. No. 3. pp. 227-239.

12. Тарасевич Ю.И. Поверхностные явления на дисперсных материалах. Киев. Наукова думка. 2011.390 с.

13. Yang R.T., Baksh M.S.A. // AIChE Journal. 1991. Vol. 37. No 5. pp. 679-686. 
14. Molinard A., Vansant E.E. // Adsorption. 1995. Vol. 1. No 1. pp. 49-59.

15. Zhu H.Y., Vansant E.F. // Journal of Porous Materials. 1995. Vol. 2. No 1. pp. 107-113.

16. Конькова Т.В., Алехина М.Б., Ахназарова С.Л., Михайличенко А.И. // Хим. технология. 2014. Т. 15. № 6. С. 333-337.

17. Ахназарова С. Л., Кафаров В. В. Методы оптимизации эксперимента в химической технологии. М. Высшая школа. 1985. 327 с.

18. Иванова Е.Н., Дудоладов А.О., Алехина М.Б., Конькова Т.В. // Успехи в химии и хи-

\section{References}

1. Shumyatskii Yu.I. Promyshlennye adsorbtsionnye protsessy, M., KolosS Publ., 2009, $184 \mathrm{p}$.

2. Stepanova M.A., Magazine «RITM», 2012, Vol. 72, No 4, pp. 102-104.

3. Akulov A.K., J. Sfera. Neft' i gaz, 2014, Vol. 42, No 4, pp. 38-42.

4. Vasil'ev A.A., Industriya, 2010, Vol. 98, No 4, pp. 44-45.

5.Kiselev A.V. Mezhmolekulyarnye vzaimodeistviya $\mathrm{v}$ adsorbtsii i khromatografii (Intermolecular Interactions in Adsorption and Chromatography). M., Vysshaya Shkola Publ., 1986, $360 \mathrm{p}$.

6. Alekhina M.B., Kon'kova T.V., Vestnik $V G U$, seriya: khimiya, biologiya, farmatsiya, 2011, No 2, pp. 67-74.

7. Vahrusheva E.M., Ivanova E.N., Alekhina M.B., Konkova T.V. et al., Uspekhi v himii I himicheskoj tekhnologii, 2013, Vol. 27, No 7 (147), pp. 80-84.

8. Brindley G.W., Sempels R.E., Clay Minerals, 1977, Vol. 12, No 3, pp. 229-237.

9. Scnoonheydt R.A., van den Eynde G., Tubbax H. et al., Clays and Clay Minerals, 1993, Vol. 41, No 5, pp. 598-607.

10. Bottero J.Y.,Cases J.M., Flessinger F., Polrler J.E., J. Phys.Chem., 1980, Vol. 84, No 22, pp. 2933-2939.

11. Zhu H., Lu G., J. of Porous Materials, 1998, Vol. 5, No 3, pp. 227-239.

Иванова Екатерина Николаевна - аспирант 4-ого года обучения факультета Технологии неорганических веществ и высокотемпературных материалов Российского химикотехнологического университета имени Д.И. Менделеева, Москва мической технологии. 2015. Т. 28. № 6 (155). C. 19-21.

19. Алехина М.Б., Иванова Е.Н., Бурмистрова Н.Н. // «Актуальные проблемы теории адсорбции, пористости и адсорбционной селективности», материалы III Всероссийской конференции с международным участием, 17-21 октября 2016 г. Москва, 2016. С. 169170 .

20. Конькова Т.В. Алехина М.Б., Рысев А.П., Садыков Т.Ф. и др. // Перспективные материальь. 2013. № 2. С. 58-63.

12. Tarasevich Yu.I. Poverkhnostnye yavleniya na dispersnykh materialakh (Surface phenomena on disperse materials). Kiev, Naukova dumka Publ., 2011, 390 p.

13. Yang R.T., Baksh M.S.A., AIChE J., 1991, Vol.37, No 5, pp. 679-686.

14. Molinard A., Vansant E.E., Adsorption, 1995, Vol. 1, No 1, pp. 49-59.

15. Zhu H.Y., Vansant E.F., J. of Porous Materials, 1995, Vol. 2, No 1, pp. 107-113.

16. Kon'kova T.V., Alekhina M.B., Akhnazarova S.L., Mikhailichenko A.I., Khim. tekhnologiya, 2014, Vol. 15, No 6, pp. 333-337.

17. Akhnazarova S.L., Kafarov V.V. Metody optimizatsii eksperimenta $\mathrm{v}$ khimii i khimicheskoi tekhnologii (Methods of Experiment Optimization in Chemistry and Chemical Engineering). Moscow, Vysshaya Shkola Publ., $1985,327 \mathrm{p}$.

18. Ivanova E.N., Dudoladov A.O., Alekhina M.B., Konkova T.V. Uspekhi v himii I himicheskoj tekhnologii, 2015, Vol. 28, No 6 (155), pp. 19-21.

19. Alekhina M.B., Ivanova E.N., Burmistrova N.N. "Aktualnye problem teorii adsorbcii, poristosti i adsorbcionnoj selektivnosti», proceedings of the III conference with international participation, Oktober 17-21, 2016, Moscow, 2016, pp. $169-170$

20. Kon'kova T.V. Alekhina M.B., Rysev A.P., Sadykov T.F. et al., Perspektivnye materialy, 2013, No 2, pp. 58-63.

Ivanova Ekaterina N. - the postgraduate student, department of technology of inorganic substances and electrochemical processes, D.I. Mendeleyev University of Chemical Technology of Russia, Moscow, E-mail: ivkatushka@gmail.com 
Бурмистрова Наталья Николаевна - магистрант 2-ого года обучения факультета Технологии неорганических веществ и высокотемпературных материалов Российского химикотехнологического университета имени Д.И. Менделеева, Москва

Алехина Марина Борисовна- доктор химических наук, доцент, профессор кафедры Технологии неорганических веществ и электрохимических процессов Российского химикотехнологического университета имени Д.И. Менделеева, Москва

Дудоладов Александр Олегович - аспирант 1-ого года обучения факультета Технологии неорганических веществ и высокотемпературных материалов Российского химикотехнологического университета имени Д.И. Менделеева, Москва

Конькова Татьяна Владимировна - к.т.н., доцент, доцент кафедры технологии неорганических веществ и электрохимических процессов Российского химико-технологического университета имени Д.И. Менделеева, Москва

Маслова Ольга Андреевна - к.ф.-М.н., доцент кафедры физической и неорганической химии Алтайского государственного университета, Барнаул
Burmistrova Natalya N. - past master, department of technology of inorganic substances and electrochemical processes, D.I. Mendeleyev University of Chemical Technology of Russia, Moscow,

E-mail:

Burmistrova.natasha1994@yandex.ru.

Alekhina Marina B. - doctor of chemical Sciences, associate prof., department of technology of inorganic substances and electrochemical processes, D.I. Mendeleyev University of Chemical Technology of Russia, Moscow, E-mail: mbalekhina@yandex.ru

Dudoladov Alexander 0. - the postgraduate student, department of technology of inorganic substances and electrochemical processes, D.I. Mendeleyev University of Chemical Technology of Russia, Moscow, E-mail: nerfangorn@gmail.com

Konkova Tatiana V. - candidate of technical Sciences, associate prof., department of technology of inorganic substances and electrochemical processes, D.I. Mendeleyev University of Chemical Technology of Russia, Moscow, E-mail: kontat@list.ru.

Maslova Olga.A. - candidate of physical and mathematical Sciences, associate prof., department of physical and inorganic chemistry, Altai State University, Barnaul, Email: maslova_o.a@mail.ru 